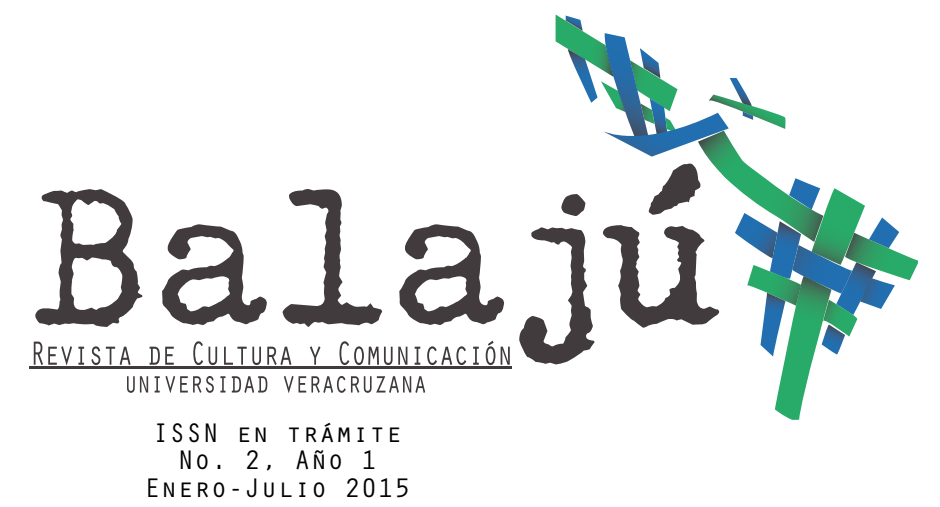

\title{
Constructores en el arte de imprimir: editores, impresores y preceptores. Florencio Aburto y Agustín Ruiz, 1847-1878
}

Marisol Alarcón Morales*

Benemérita Universidad Autónoma de Puebla, México sol.alarcon26@gmail.com

* Estudiante de la maestría en Historia del Instituto de Ciencias Sociales y Humanidades Alfonso Vélez Pliego

\section{RESUMEN}

Los estudios de la labor realizada por los impresores decimonónicos y la profesionalización del quehacer periodístico han adquirido relevancia entre los estudiosos de la cultura, la prensa y el periodismo; a pesar de su importancia, siguen siendo escasos. Por ello, en este texto se presenta la labor y la producción editorial de Florencio Aburto y de Agustín Ruiz, actores sociales que conjuntaron una actividad intelectual en el mundo de la impresión, el diseño y la edición, convertidos en los principales impulsores de la cultura escrita en la ciudad de Xalapa de las primeras cuatro décadas del siglo XIX.

\begin{abstract}
The studies of the labor realized by the nineteenth-century printers and the professionalization of the journalistic occupation have acquired relevancy between the experts of the culture, the press and the journalism; in spite of his importance they continue being scanty. For it, in this text one presents the labor and the publishing production of Florencio Aburto and of Agustín Ruiz, social actors who combined an intellectual activity in the world of the impression, design and edition, turned into the principal impellers of the culture written in Xalapa's city of the first four decades of the 19th century.
\end{abstract}

\section{PALABRAS CLAVES}

Prensa, siglo XIX, impresores, Xalapa, periódicos.

\section{KEYWORDS}

Press, 19th century, printers, Xalapa, newspapers. 


\title{
Constructores en el arte de imprimir: editores, impresores y preceptores. Florencio Aburto y Agustín Ruiz, 1847-1878
}

\author{
Noble y dedicada es la misión del periodista \\ cuando llena de conciencia, pundonor y \\ buena fe, consagra sus vigilas en obsequio de \\ la causa pública, desenvolviendo sus ideas \\ por medio del buen juicio y del recto raciocinio. \\ La Sombra de Gutiérrez Zamora, 1873
}

No existe hasta el día de hoy ningún antecedente que determine con exactitud quién introdujo la imprenta en la ciudad de Xalapa. Sin embargo, los historiadores José Toribio y Leonardo Pasquel señalan que hacia el año de 1807 circuló una publicación llamada La Gaceta, que aparentemente aparecía de manera quincenal ${ }^{1}$, aunque no se ha encontrado ejemplar alguno de dicho impreso. Será hasta el año de 1824 cuando se sepa con certeza de la aparición del periódico El Oriente, editado por Sebastián Camacho, quien lo utilizaría como un medio para difundir las acciones realizadas por la primera Legislatura de Veracruz durante las sesiones extraordinarias.

Entre revistas, folletos, boletines y periódicos, Sebastián Camacho, Florencio Aburto y Agustín Ruiz impulsaron una actividad cultural de gran relevancia que los coloca como pioneros en la introducción y establecimiento de la imprenta en Xalapa, así como de la impresión y difusión de las primeras publicaciones periodísticas. Pocos trabajos tratan sobre la vida y obra de estos hombres dedicados al arte de escribir, razón por la cual nos hemos ocupado de avanzar un poco en sus biografías e investigar sobre la producción editorial de sus imprentas.

\section{Florencio Aburto: preceptor e impresor-editor}

Florencio Aburto nació en Veracruz en $1805^{2}$ y estuvo casado con Paula Rivas, albacea de su fortuna después de su muerte ${ }^{3}$. Aburto poseía grandes conocimientos de música y de gramática, y dominaba los idiomas inglés y francés, lo que le permitió desempeñarse como impresor, político y preceptor, sobresaliendo entre los personajes xalapeños más importantes de la primera mitad del siglo XIX.

En sus inicios como impresor, Aburto alquilaba una imprenta que

1 María del Carmen Ruiz Castañeda, “La prensa durante el Primer Imperio y la República Federal”, en Luis Reed Torres y María del Carmen Ruiz Castañeda, El periodismo en México, 450 años de historia, p. 125.

2 AHMX, caja 15, 1855, exp. 6, f. 11.

3 AHMX, libro 76, 1864, f. 75. 
se encontraba en el puerto de Veracruz, propiedad de Carlos M. Terán. $\mathrm{Al}$ parecer, en 1837 adquirió dicha imprenta, que fue trasladada a la ciudad de Xalapa, y con ella estableció su taller, que también funcionó como librería y domicilio particular. Allí se editaban oraciones del catecismo doctrinal y silabarios utilizados para la formación educativa en las escuelas parroquiales y en las "Amigas", casas particulares que funcionaban como espacios educativos, dirigidas a niñas de 3 a 10 años de edad, donde una mujer o un grupo de mujeres se encargaban de enseñarles la doctrina cristiana y a bordar, coser y tejer; aunque en algunas "Amigas" también se enseñaba a leer y a escribir ${ }^{4}$. Esta imprenta amplió más tarde su edición de cartillas de gramática, geografía e historia, que seguramente formaron parte de la currícula de la enseñanza elemental ${ }^{5}$. La importancia que fue adquiriendo se dejó ver a través del establecimiento de corresponsales en distintos puntos de la ciudad, del estado y del país.

El 6 de agosto de 1834, el Departamento de Educación del Ayuntamiento de la ciudad de Xalapa expidió a Florencio Aburto el título de preceptor de la escuela Pía de Boza ${ }^{6}$, establecimiento fundado en el siglo XVIII y dirigido a niños pobres, el cual subsistiría a lo largo del siglo XIX, pese a las diversas disposiciones educativas que los cambios políticos ocasionaron durante esa centuria y pese a los problemas económicos que tuvo, ya que en algunos periodos dicha escuela perdió los fondos que le daba el Ayuntamiento, por lo que hubo de permanecer cerrada. Ante esa catastrófica situación, sus directores implementaron diversas estrategias para sobrevivir, como obtener el apoyo de los mismos preceptores para presionar al Ayuntamiento en cuanto a los pagos del ramo de la instrucción pública, así como para obtener otros financiamientos y seguir a cargo de la educación de los niños7.

Como preceptor de esa escuela, Florencio Aburto no sólo estuvo al pendiente de su financiamiento, sino que gracias a su conocimiento del ambiente educativo también propuso y reformó los cuadernillos escolares según las necesidades de aprendizaje de los niños. Sugirió y escribió diversas partituras musicales, enseñó el manejo del florete en la clase de esgrima y se encargó de la encuadernación de libros.

4 Claudia López Aburto, La enseñanza primaria superior para niñas xalapeñas (1873-1910), p. 10.

5 Leonardo Pasquel, Revista Jarocha, dedicada al periodismo Veracruzano, p. 45.

6 AHMX, caja 15, 1855, exp. 6, f. 11. El sueldo que recibía Florencio Aburto como preceptor de la Escuela Pía de Boza era de 16 pesos mensuales, cubiertos por el Ayuntamiento, y los réditos de 8110 pesos de la testamentaria de Boza.

7 AHMX, caja 9, 1849, f. 1 


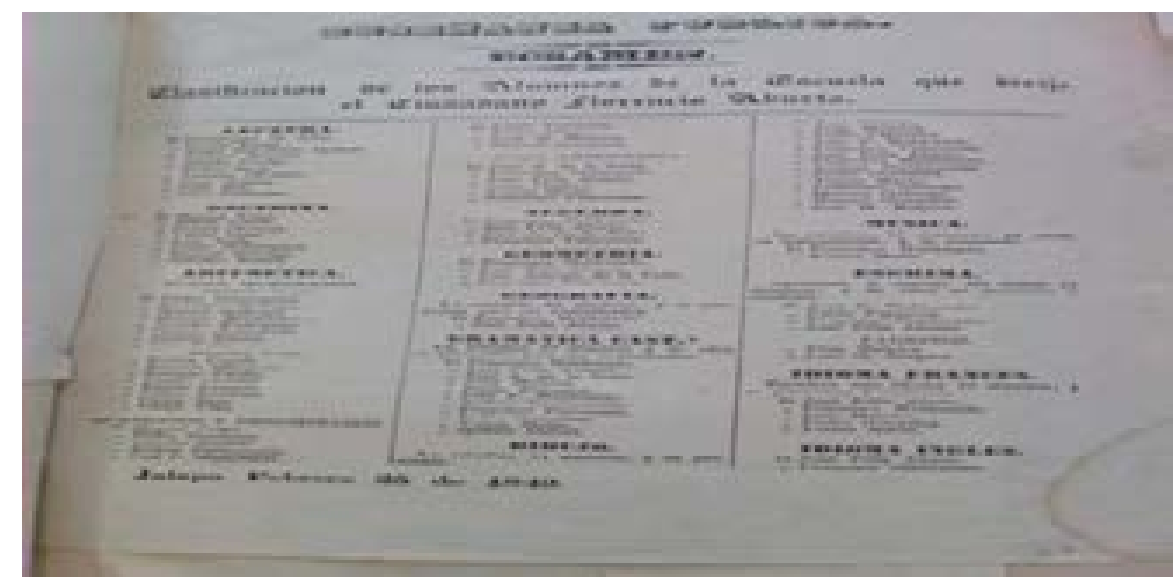

Figura 1. Cuadernillo escolar, 25 de febrero de 1849

Florencio Aburto tenía 50 años de edad cuando el Ayuntamiento de Xalapa realizó, en 1855, el primer informe sobre las condiciones que debía reunir un preceptor. Dicho informe contenía una relación de la edad, nacionalidad, religión, conducta, así como la especificación de si contaba con título o no, el tiempo ejercido y el sueldo devengado. Aburto fue el único que había recibido el título de preceptor por el gobierno del Departamento de Instrucción Pública el 6 de agosto de 1834, cuando llevaba 21 años ejerciendo ese puesto, y fue además reconocido como un hombre de buena conducta, facultado para seguir desempeñando satisfactoriamente su título ${ }^{8}$.

En compañía de Antonio María de Rivera, Florencio Aburto y otros maestros veracruzanos, decidieron fundar el Colegio Nacional de Jalapa, el 16 de septiembre de 1843. Allí Aburto impartió las cátedras de gramática castellana y de geografía; además, en 1857 fue miembro de la Junta Patriótica, cuya principal función fue la de promover entre los xalapeños un espíritu patriótico.

Dentro del mundo de la impresión y de la edición, su trabajo se puede apreciar en la multitud de libros, folletos, calendarios, periódicos, memorias, discursos, reglamentos, boletines para la instrucción pública, decretos, avisos y sellos que editó. Su imprenta tuvo larga vida y en ella se imprimieron los periódicos El Amigo de la Paz, El Orden y El Negador, desde 1835 hasta 1877 . No obstante, a partir de 1865 el pie de imprenta de estas publicaciones sufrió una modificación, apareciendo como "Imp. De Aburto e hijos"; ya para esas fechas Florencio había muerto. Un acta de cabildo confirma, en efecto, que murió en 1864, cuando tenía 54 años de edad ${ }^{10}$. En sus últimos años comenzó a declinar la producción de su taller, y poco a poco fue desapareciendo su sello, que para entonces ya

8 AHMX, caja 15, 1855, exp. 6, f. 11.

9 AHMX, caja 17, 1857, exp. 11, f. 3.

10 AHMX, libro 76, 1864, f. 75. 
tenía una reñida competencia con La Imprenta Veracruzana, propiedad de Agustín Ruiz.

A diferencia de las imprentas que funcionaron en la villa de Xalapa, durante el primer cuarto del siglo XIX la de Aburto no sólo evolucionó en el tiraje de los periódicos, sino también utilizó nueva litografía. Desde 1835 hasta 1877 tuvo una variada producción, aunque los periódicos fueron sus publicaciones más importantes, llegando a ocho: El Amigo de la Paz y el Orden (1835), El Conciliador (1839), El Nacional (1841), El Zempoalteca (1845), El Boletín de la Revolución (1855), El Boletín de Jalapa (1865), La Regeneración (1876) y El Negador (1877).

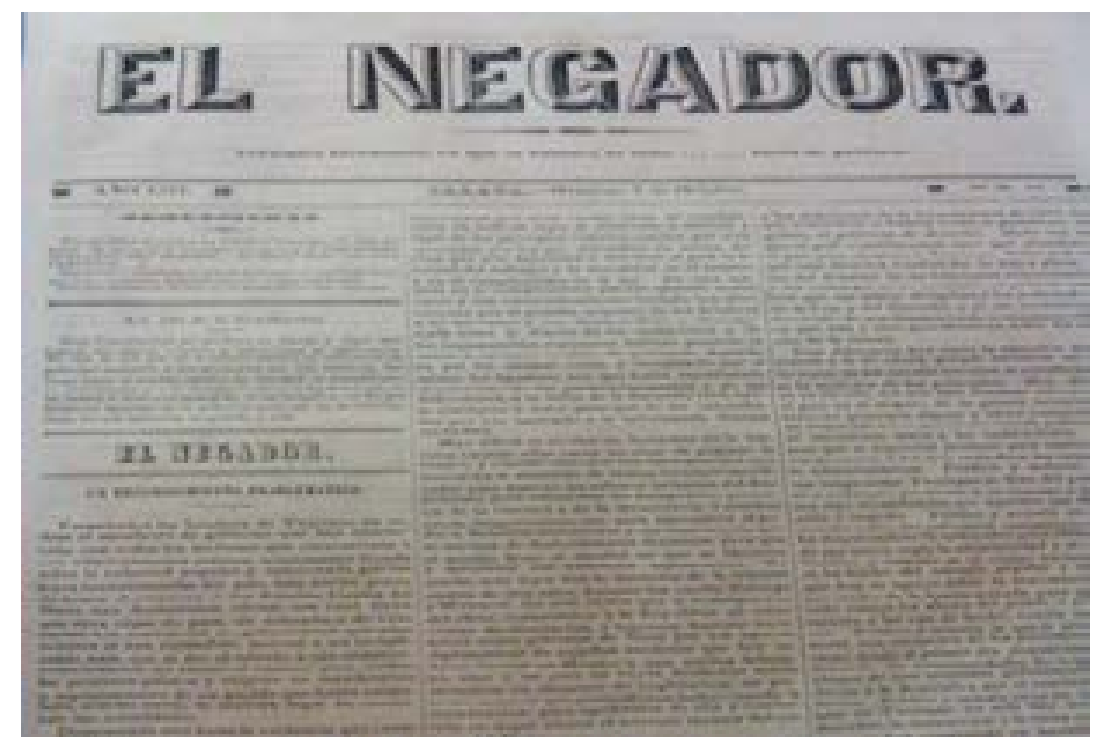

Figura 2. El Negador, 7 de octubre de 1877, núm. 16

En su labor como director e impresor de dichos periódicos, Florencio Aburto transformó la actividad editorial. Entre sus aportaciones podemos mencionar que, a diferencia de los diarios impresos en el puerto de Veracruz, los editados en su taller fueron pioneros en incluir los costos de inserción de páginas, además de que sus interiores mostraron diversidad de temáticas y contenidos, y su innovador formato permitió el incremento en la producción ${ }^{11}$.

\section{Imprenta Veracruzana de Agustín M. Ruiz: editor conservador}

Muchas incógnitas rodean la vida de Agustín M. Ruiz, pues hasta el día 11 Por ejemplo, los periódicos impresos en Veracruz como La Gaceta del Real Tribunal del Consulado de Veracruz (1795) y Jornal Económico Mercantil (1805), editados por Manuel López Bueno, daban cuenta de las llegadas y salidas de los barcos, las cargas de los mismos y los artículos de exportación e importación. No contaban con secciones específicas como las que se manifestaron desde la impresión de El Oriente (1824), que posteriormente se definieron en los talleres de Aburto. Tal es el caso de El Conciliador (1839), que daba cuenta de avisos, correspondencia, cartelera teatral, precios y distribución. 
de hoy no se ha encontrado algún documento que esclarezca sus primeros años. Por el historiador Leonardo Pasquel sabemos que se estableció en 1875 en la ciudad de Xalapa; la llamada Imprenta Veracruzana estaba ubicada en la primera calle de Zamora, y en 1900 fue adquirida por el Gobierno del Estado.

A través del análisis de su producción de impresos periodísticos, es posible deducir que Agustín M. Ruiz fue un hombre de tinte conservador, católico e intervencionista. Así lo hace pensar el hecho de que en su órgano se publicara el Dictamen sobre la forma de Gobierno para la República, el cual proponía que la nación mexicana adoptara la forma de gobierno de la monarquía moderada, suceso que se manifestó después de la huida de Juárez al norte del país, y de que el archiduque austriaco Maximiliano de Habsburgo fuese proclamado emperador de México, el 3 de octubre de $1863^{12}$.

Agustín Ruiz simpatizaba con la idea de establecer una monarquía hereditaria con un príncipe, postura que lo llevó a difundir, a través de sus periódicos, noticias sobre Maximiliano y sobre la guerra que los militares conservadores y el ejército francés libraban contra los juaristas. También daba cuenta de las actividades de la Iglesia y de los horarios de misas. El definido perfil conservador de sus periódicos se observa, por ejemplo, en el caso de La Opinión de Jalapa (1864), cuyos artículos proclamaban entusiastamente el Segundo imperio.

Sin embargo, Agustín Ruiz también editaba periódicos con perfil liberal, como El Demócrata (1868) y El Despertador (1869). Entonces no sólo divulgaba noticias vinculadas al imperio, sino que, como todo negocio, también consideraba la edición de diversos impresos, propaganda política y circulares del gobierno, aparte de los periódicos. Su imprenta funcionó alrededor de 13 años y jugó un papel importante en el medio editorial. Fue en La Opinión de Jalapa (1864) donde por primera vez aparecieron simultáneamente en la prensa xalapeña la sección editorial, la oficial y la gacetilla.

El taller de Agustín Ruiz no sólo vendía tipos de impresiones nuevas, sino también de medio uso, e inclusive llegó a ofrecer un Brevario, mejor conocido como "Abecedario completo". Además tuvo a la venta un variado surtido de libros de religión, educación, jurisprudencia, legislación, ciencia, literatura, arte, historia, bellas letras, novelas, comedias, libros elementales y libros en blanco. Complementariamente vendió papel pautado, rayado horizontal y para cuentas, reconocimientos, recibos para el cobro de fincas, papel para cartas y esquelas, plumas, portaplumas, sobres para oficio, papel secante, lacre, papel de luto y frascos de

12 Konrad Ratz, Maximiliano de Habsburgo, p. 156. 
goma líquida, entre otros productos.

De México y del puerto de Veracruz recibía un amplio surtido de libros elementales, los cuales catalogaba e imprimía en una lista para conocimiento del público. A precios módicos llegó a imprimir tarjetas de mosaicos en imitación concha, la última novedad en París. Y como publicidad anunciaban que: "Todas las impresiones que se hagan en este establecimiento reunirán cualidades de corrección, prontitud y baratura"13. A su variedad de productos debe añadirse las tarjetas de días festivos, papeletas de entierro, circulares y recibos; y respecto a difusión, diseñaba los anuncios que se le encargaban e incluso hacía traducciones de un idioma a otro, en especial del inglés o del francés, a precios convencionales.

En este taller se editaron obras del escritor, político y militar Vicente Riva Palacio; por ejemplo Calvario y Tabor, novela vendida al precio de un real. Allí se recibía la suscripción para obtener tal publicación, que contenía ilustraciones del artista Constantino Escalante. Editó asimismo la Historia antigua y moderna de Jalapa, escrita por Manuel Rivera Cambas, y obras del barón de Humboldt.

De la producción de periódicos de su imprenta se conoce el tiraje de ocho: La Opinión de Jalapa (1862), El Despertador (1868), El Demócrata (1868), El Pensamiento (1871), La Sombra de Gutiérrez Zamora (1873), El Obrero del Porvenir (1878), El Orto de la Verdad (1878), El Pueblo (1878) y La Esperanza (1878). En ellos se dieron a conocer diferentes opiniones políticas y religiosas, pues unos eran de tinte conservador -entre éstos, los periódicos religiosos- y los menos, de tendencia liberal.

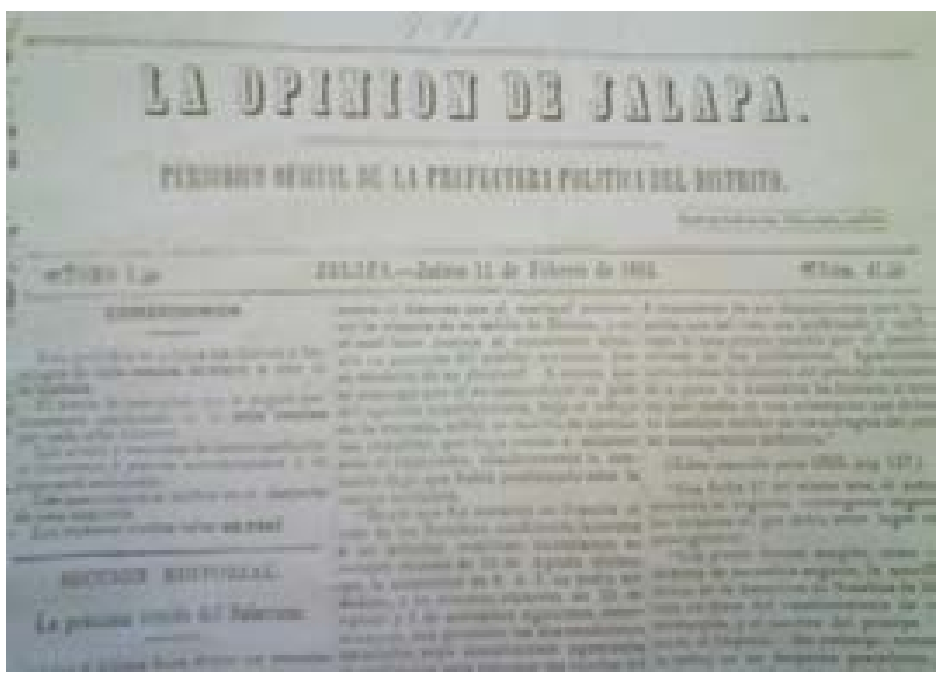

Figura 3. La Opinión de Jalapa, 11 de febrero de 1864

13 El Pensamiento, agosto de 1871, núm. 13. 


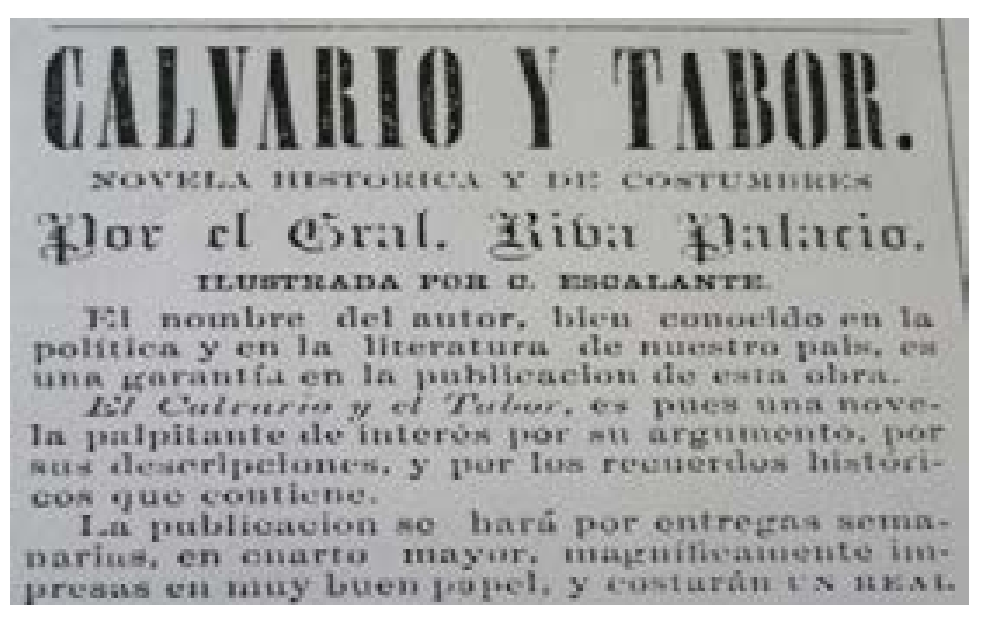

Figura 4. Anuncio de El Demócrata, 1868

\section{Palabras finales}

La labor editorial realizada por Florencio Aburto y Agustín Ruiz contribuyó a la transformación y el desarrollo de la imprenta xalapeña decimonónica. Su producción editorial funcionó como vocera, representante y defensora de derechos e intereses que respondieron a las necesidades de las élites ilustradas; los impresos principalmente periodísticos formaron parte de las nuevas estructuras culturales, políticas, sociales y económicas en construcción de esa ciudad.

Las imprentas de Aburto y Ruiz propiciaron cambios en los formatos y técnicas de impresión, en la compra de novedosos materiales importados, en la utilización de la litografía y de los grabados, así como en el mecanismo de venta de distribución. Su producción de periódicos, folletos, hojas sueltas, cuadernillos, hojas membretadas, circulares y cartas permitió la ampliación de la palabra escrita, convirtiéndolos en empresarios prósperos, con negocios prósperos provistos de corresponsales y de espacios de venta y distribución. El quehacer editorial de uno y otro redundó no sólo en su beneficio personal fincado en las labores de impresión, sino también en sus intereses políticos y en sus inquietudes culturales y educativas.

\section{Siglas}

AHMX. Archivo Histórico Municipal de Xalapa. 


\section{Hemerografía}

El Demócrata, Jalapa 1868.

El Pensamiento, Jalapa, 1871.

La Opinión de Jalapa, 1864.

El Negador, Jalapa, 1877.

\section{Bibliografía}

BLÁZQUEZ DOMÍNGUEZ, Carmen. Colección de leyes y decretos de Veracruz, 1824-1919. Tomos I y II, Gobierno del Estado de Veracruz, Xalapa, 1997.

. Xalapa, Veracruz: imágenes de su historia, Gobierno del Estado de Veracruz, Xalapa, 1990.

. Breve historia de Veracruz. Fondo de la Cultura Económica, México, 2000.

. "Escoses y yorkinos. La crisis de 1827 y el pronunciamiento de José Rincón en el Puerto de Veracruz”, en Anuario VII. Universidad Veracruzana-Centro de Investigaciones Históricas, 1989.

. Políticos y comerciantes de Veracruz y de Xalapa, 1827-1829. Gobierno del Estado de Veracruz, Xalapa, 1992 (Colección V Centenario).

BRAVO MORALES, Gladis. El periodismo en Veracruz. Tesis de licenciatura en Historia, Universidad Veracruzana, 1971.

CHARTIER, Roger. El mundo como representación. Historia cultural: entre práctica y representación. Gedisa, México, 1992.

CIRUELO TORRES, Gerardo. Grupos de poder y ayuntamiento en Xalapa: élites, administración municipal y poder político en los inicios de la República federal, 1824-1829. Tesis de licenciatura, Facultad de Historia, Universidad Veracruzana, Xalapa, 2002.

CONDUMEX. Impresos mexicanos del siglo XVI (Los Incunables). Ediciones Equilibrista, México, 1995.

DEL PALACIO MONTIEL, Celia. La prensa como fuente para la Historia. Porrúa, México, 2006.

. Catálogo de la hemerografía de Veracruz. 1795-1950. Universidad de Guadalajara-Conacyt, Guadalajara, 2005.

FLORESCANO MAYET, Sergio. "Xalapa y su región durante el siglo XIX: las principales vertientes de su desarrollo económico, social y cultural”, en La Palabra y el Hombre. Julio-septiembre, Universidad Veracruzana, Xalapa, 1992. 
GOMEZJARA, Francisco A. Xalapa. Editorial Gobierno del Estado de Veracruz, Xalapa, 1998.

GONZÁLEZ DE COSSÍO, Francisco. Xalapa: breve reseña histórica. Talleres Gráficos de la Nación, México, 1957.

GUERRA, François Xavier. México: del Antiguo Régimen a la Revolución. Fondo de Cultura Económica, México, 1985.

LÓPEZ ABURTO, Claudia. La enseñanza primaria superior para niñas xalapeñas (1873-1910). Tesis de licenciatura en Historia, Universidad Veracruzana, Xalapa, 2012.

PASQUEL, Leonardo. Revista Jarocha, dedicada al periodismo Veracruzano. Año V, núm. 27-28, Citlaltépec, México, 1963.

PICATTO, Pablo. "Jurados de imprenta en México: el honor en la construcción de la esfera pública, 1821-1882”, en Paula Alonso (comp.), Construcciones impresas. Panfletos, diarios y revistas en la formación de los estados nacionales en América Latina, 1820-1920. Fondo de Cultura Económica, México, 2003.

RATZ, Konrad. Maximiliano de Habsburgo. Planeta De Agostini, México, 2002.

RIVERA CAMBAS, Manuel. Historia antigua y moderna de Xalapa y de las revoluciones del Estado de Veracruz. Estudio preliminar de Leonardo Pasquel, tomos II-V, Citlaltépec, México, 1959.

RODRÍGUEZ Y SÁINZ, Gustavo A. Historia precortesiana de Xalapa. Talleres gráficos El Aventino, México, 1931.

RUIZ CASTAÑEDA, María del Carmen. "La prensa durante el Primer Imperio y la República Federal", en Luis Reed Torres y María del Carmen Ruiz Castañeda, El periodismo en México, 450 años de historia. Tradición, México, 1974.

SOLARES ROBLES, Laura. "Justicia y libertad de imprenta en el siglo XIX: 1821-1855”, en Celia del Palacio Montiel y Adriana Pineda Soto (coords.), Prensa decimonónica en México. UdeG-UMSNH, México, 2003.

"La organización de la justicia. Una mirada a través de la folletería mexicana del siglo XIX, 1821-1857", en Secuencia. Núm. 39, septiembre-diciembre, 1997.

. "Justicia y libertad de imprenta. ¿Términos afines? 1821-1831", en Celia del Palacio Montiel (comp.), Historia de la prensa en Iberoamérica. Alianza del texto universitario, México, 2000.

SPINOSO ARCOCHA, Rosa María. "Xalapa, la Bella: metáforas femeninas y economía mercantil (siglos XVIII y XIX)”, en Fernanda Núñez Becerra, Rosa María Spinoso (coords.), Mujeres en Veracruz. Gobierno del Estado de Veracruz, Xalapa, 2008. 
TRENS, Manuel B. Historia de Veracruz. T. IV, SEC, Xalapa, 1920.

VÁSQUEZ, Josefina Zoraida. El establecimiento del federalismo en México, México 1821-1827. El Colegio de México, México, 2003.

VON WOBESER, Gisela. "La consolidación de vales reales como factor determinante de la lucha por la independencia en México, 18041808”, Historia Mexicana. Vol. LVI, núm. 2, El Colegio de México, 2006.

ZÁRATE TOSCANO, Verónica. "Los albores del periodismo veracruzano: el Jornal Económico Mercantil de Veracruz como fuente histórica”, en Secuencia. Núm. 33, septiembre-diciembre, 1995.

ZÓCALO. Prensa e Independencia, suplemento 1, enero 2010. . La Prensa en el siglo XIX, suplemento 2, marzo 2010. . Periodistas del siglo XIX, suplemento 3, mayo 2010. 